\title{
REIVINDICACIÓN DE ROUSSEAU
}

José Francisco Bellod Redondo*

L os textos que hoy se usan habitualmente en la enseñanza de las doctrinas económicas suelen omitir o mencionar de prisa al filósofo y enciclopedista Jean-Jacques Rousseau (1712-1778). Prueba de ello es el libro de Schumpeter (1954), decano de los historiadores del pensamiento económico actual, que despacha a Rousseau en unas cuantas líneas, que no solo reflejan un evidente anacronismo sino también un tono desdeñoso y despectivo:

J.-J. Rousseau (1712-1778) no se puede considerar socialista, pese a su glorificación del estado natural de la sociedad; fue típicamente lo que queremos significar con el término "semisocialista". Pero tampoco es posible considerarle como un economista. Su artículo de economía política en la Enciclopedye no contiene casi economía. Su ensayo sobre el origen de la desigualdad (1775) no es un esfuerzo serio por explicar el fenómeno. En particular, y pese a algunas analogías superficiales en la dicción, no fue un fisiócrata ni un precursor de la fisiocracia (Schumpeter, 1982, 179-180).

En la mayoría de los manuales destinados a la formación de los economistas ni siquiera encontramos referencias a Rousseau, exclusión que, como mínimo, debería extrañarnos pues fue un pensador de una talla intelectual y una trascendencia histórica muy superior a la de sus contemporáneos, que sí han encontrado un cálido nicho en esos manuales, como Turgot, Quesnay o Du Pont de Nemours. Sin embargo, numerosas investigaciones atestiguan la relevancia de Rousseau en la historia del pensamiento económico ${ }^{1}$.

* Doctor en Economía, profesor del Departamento de Fundamentos del Análisis Económico, Universidad de Murcia, España, [bellodredondo@yahoo.com]. Fecha de recepción: 3 de septiembre de 2014, fecha de modificación: 7 de abril de 2016, fecha de aceptación: 12 de mayo de 2016. Sugerencia de citación: Bellod R., J. F. "Reivindicación de Rousseau", Revista de Economía Institucional 18, 34, 2016, pp. 29-37. DOI: http://dx.doi.org/10.18601/01245996.v18n34.03

${ }_{1}^{1}$ Ver, p. ej. Hénaff (1989), Markovits (1991), Fridén (1998), Spector (2003), Cervellati et al. (2005), Larrère (2007), Pignol (2010, 2011) o Cabrales et al. (2012). 
El objetivo de este ensayo es analizar la pertinencia de esa exclusión. Empleamos la expresión "pertinencia de" para denotar que su contribución no es "sobrante", y no el término "corrección”, sinónimo de estar libre de errores y defectos. En la primera sección reseñamos los aportes más relevantes de Rousseau al pensamiento económico y argumentamos que perteneció a la escuela fisiocrática. En la segunda exploramos las posibles causas de su marginación en la historia del pensamiento económico. Al final presentamos unas conclusiones.

\section{EL PENSAMIENTO FISIÓCRATA EN LA OBRA DE ROUSSEAU}

Para clasificar el pensamiento económico de Rousseau partimos de la advertencia de Cassirer (1984) y Todorov (2008) en sus trabajos sobre la Ilustración: a diferencia de lo que se suele creer, los pensadores de la Ilustración no formaron una escuela homogénea y había grandes discrepancias entre ellos. Puesto que no tenían plena identidad en el pensamiento económico ni en otros campos, tampoco la tenían en sus análisis ni en sus propuestas, aunque compartieran elementos comunes del pensamiento ilustrado.

En contra de lo que sostiene Schumpeter, en los escritos económicos de Rousseau se encuentran muchas ideas y conceptos de la escuela fisiócrata, que era hegemónica en la época y en el país de economía agraria en que vivió. La fisiocracia fue un movimiento intelectual típicamente francés que surgió y se difundió en el siglo XVIII, cuya relevancia ha sido injustamente ensombrecida por el predominio del pensamiento económico británico y de su figura más destacada, Adam Smith.

Cabe mencionar algunas ideas fisiocráticas que se encuentran en esos escritos: la invocación de la ley natural como principio explicativo, la condena del lujo, la preocupación por el descenso de la población en el campo en favor de la ciudad, la distinción entre trabajo productivo (en la agricultura) e improductivo (en el comercio y la manufactura), la defensa de un impuesto único y de un sistema fiscal más progresivo ${ }^{2}$ $y$, por último, un ataque frontal a los principios del mercantilismo.

Igual que los demás fisiócratas, Rousseau considera la agricultura como única fuente de riqueza (excedente), de modo que juzga conveniente remover las trabas a su libre desarrollo. E1 lujo de los rentistas y los altos funcionarios públicos, así como las cargas tributarias impuestas a la agricultura para desarrollar y sostener a las ciudades y a sus habitantes, son lastres para la prosperidad:

${ }^{2}$ Para su teoría monetaria, ver Pignol (2010).

Revista de Economía Institucional, vol. i8, N. ${ }^{\circ}$ 34, Primer semestre/2oi6, pp. 29-37 
A medida que la industria y las artes se extienden y florecen, el agricultor es despreciado, cargado de impuestos, necesarios para el sostenimiento del lujo, y condenado a pasar su vida entre el trabajo y el hambre, abandona al fin sus campos para ir a las ciudades en busca del pan que debería traer a ellas. Mientras más admiración causen las capitales a los ojos estúpidos del pueblo, más tendremos que sufrir viendo las campiñas abandonadas, las tierras sin cultivo y los caminos inundados de desgraciados ciudadanos convertidos en mendigos o en ladrones (Rousseau, 2012, 201-202).

Con respecto al sistema tributario, una de las herramientas fundamentales de la política económica fisiocrática, Rousseau consideró que penalizaba a la actividad agrícola:

La tasa sobre tierras o sobre el trigo, y más si es excesiva, da lugar a dos inconvenientes tan nefastos que a la larga acaban despoblando y arruinando el país en el que se instaura [...]

E1 primero proviene de la falta de circulación en especie, pues el comercio y la industria acopian en la capital todo el dinero del campo. Al desbaratarse la proporción del impuesto que aún podía darse entre las necesidades del labrador y el precio del trigo, el dinero sale continuamente y no regresa jamás: cuanto más rica es la ciudad tanto más miserable es el campo. El producto de las tallas ${ }^{3}$ pasa de manos del príncipe o del financiero a manos de artesanos y comerciantes, y el cultivador, que solo percibe la menor parte, se desgasta al tener que pagar lo mismo para recibir siempre menos (Rousseau, 2011, 72).

Y argumentó que, como la agricultura era la única fuente de riqueza, la despoblación rural -inducida por el injusto sistema tributario- era sumamente peligrosa y se requería una reforma fiscal ${ }^{4}$ :

En primer lugar, hay que considerar la relación de cantidades por la cual, siendo todas las cosas iguales, quien posea diez veces más deberá pagar diez veces más. En segundo lugar, la relación de usos, es decir, la distinción entre lo necesario y lo superfluo. Quien simplemente posee lo necesario no deberá pagar nada; la tasa del que tiene algo superfluo puede igualarse a la suma total de lo que exceda de sus bienes necesarios. Ante esto podría replicarse que, dado su rango, lo que es superfluo para un hombre inferior resulta necesario para él; pero esto es mentira, porque un "grande" tiene dos piernas como tiene un vaquerizo, y como él, tan solo tiene un vientre (ibíd., 68).

Esa propuesta muestra que Rousseau defendía una idea que aún hoy es aceptada -la existencia de un mínimo vital no gravable- y un impuesto a la renta de la tierra cuya base gravable podría llegar a ser igual al excedente sobre ese mínimo vital. Así, la estructura tributaria proporcional que habría de sustituir a la "talla real" francesa daría lugar a un impuesto progresivo, una vez descontado el mínimo exento. Aunque

${ }^{3} \mathrm{La}$ "talla real" era un impuesto directo y personal, establecido en 1439 durante la Guerra de los Cien Años, muy regresivo pues estaban exentos la nobleza, el clero y algunas ciudades.

${ }^{4}$ Para una formalización de la propuesta tributaria de Rousseau, ver Faiña et al. (2011). 
en la cita anterior puede haber cierta ambigüedad acerca del carácter real o personal de este impuesto ${ }^{5}$, Rousseau aclara así su propuesta:

Si combinamos con cuidado todos estos elementos, encontramos que para repartir las tasas de manera equitativa y verdaderamente proporcional, la imposición no debe hacerse solo en razón de los bienes de los contribuyentes, sino tomando en cuenta la razón compuesta de la diferencia entre sus condiciones y el superfluo de sus bienes (ibíd., 71).

Su condena del gusto por el lujo es inequívoca. Si para los mercantilistas el lujo era preferible a la limosna, porque promovía el empleo y prevenía la vagancia, para Rousseau era un gasto superfluo de las rentas extraídas a los agricultores, bien fuese por los rentistas o mediante el sistema tributario injusto, que perjudicaba la prosperidad de la nación.

Una de las exposiciones más elegantes de la actitud mercantilista hacia el lujo se debe al sabio Samuel Johnson (1709-1784):

Muchas cosas que son falsas se transmiten de libro en libro y ganan crédito en el mundo. Una de ellas es la denuncia del lujo como algo malo. Ahora bien, lo cierto es que el lujo produce mucho bien [...] habrá oído decir con mucha seriedad: "¿Por qué no se les dio a los pobres esa media guinea gastada en lujo? ¿A cuántos podría haber procurado una buena comida? ¡Ay! ¿Por qué no ha ido a parar al pobre trabajador, a quien es mejor apoyar que al pobre holgazán?". Esté usted bien seguro de que hace mayor bien cuando paga dinero a los que trabajan como recompensa de su trabajo, que cuando lo da meramente por caridad. Suponga que el antiguo lujo de un plato de sesos de pavo real volviera a ponerse de moda, ¡cuántos cuerpos de pavo real quedarían para los pobres a bajo precio! (Boswell, 2007, 671).

\section{Rousseau replica:}

E1 lujo imposible de evitar entre los hombres ávidos de comodidades y ansiosos de alcanzar la consideración de los demás, perfecciona en breve el mal comenzado por las sociedades; y so pretexto de aliviar las necesidades de los pobres, que no deberían existir, arruina a todos despoblando tarde o temprano el Estado [...]

E1 lujo es un remedio mucho peor que el mal que pretende curar; o más bien, es el peor de todos los males que puedan sobrevenir a cualquier nación, grande o pequeña, pues para sostener o alimentar turbas de servidores y de miserables por él creadas, abruma y arruina al labrador y al ciudadano (Rousseau, 2012, 201).

En todo caso, el lujo es una carga sobre la fuente productora de riqueza, que se puede corregir reformando el sistema fiscal:

Establézcanse fuertes tasas por libreas, la servidumbre, espejos, arañas y muebles, sobre los tejidos y dorados, patios y jardines de palacetes, espectáculos de toda especie, profesiones ociosas, como faranduleros, cantores, histriones; en una palabra, sobre toda esa caterva de objetos de lujo, diversión y ociosidad

${ }^{5}$ Son impuestos de naturaleza "real" los que gravan los hechos imponibles independientemente de las características subjetivas de la persona que los realiza. Y son impuestos "personales" los que en su configuración atienden a las características personales o subjetivas del contribuyente. 
que a todos maravillan y que no pueden ocultarse so pena de volverse sin sentido, siendo su único uso el mostrarse y ser vistos (Rousseau, 2011, 76-77).

\section{EL OPTIMISMO CAPITALISTA Y LA EXCLUSIÓN DE ROUSSEAU}

La gran dificultad para incluir a Rousseau en los manuales y textos de pensamiento económico es que, a diferencia de algunos de sus contemporáneos ilustres (p. ej., David Hume o Adam Smith), no es fácil interpretar y usar su obra de manera espuria.

Por ejemplo, David Hume fue un gran filósofo cuyos escritos sobre economía tienen una entidad mucho menor que el resto de su obra, igual que los de Rousseau. Y la parte fundamental de su obra filosófica (la teoría del conocimiento) no guarda relación visible y evidente con sus escritos económicos. De modo que es fácil aislar sus escritos sobre moneda o libre comercio, interpretarlos al margen del resto de su obra y usarlos para aprestigiar el discurso de una escuela de pensamiento económico (como han hecho los monetaristas). La obra de Adam Smith también se ha interpretado y utilizado en forma espuria: los economistas de orientación neoliberal citan sin cesar sus párrafos sobre la división del trabajo, la mano invisible y las bondades del interés privado, pero silencian su teoría del valor trabajo y muchísimos pasajes incómodos. Jamás citan, por ejemplo, las siguientes líneas del libro I, capítulo VI, de La riqueza de las naciones:

Si en una nación de cazadores, por ejemplo, cuesta habitualmente el doble de trabajo cazar un castor que un ciervo, un castor debería naturalmente intercambiarse por, o valer, dos ciervos. Es natural que el producto habitual de dos días o dos horas de trabajo valga el doble de lo que normalmente es el producto de un día o una hora de trabajo (Smith, 2015, 86).

En la obra de Rousseau es muy difícil separar sus reflexiones económicas de su obra filosófica y en particular de su teoría del Estado. Su liberalismo es una defensa de la ley natural como principio para liberar a la humanidad de todo tipo de coacción, no es una defensa del capitalismo y, por ello, es un autor "incómodo" como defensor del nuevo régimen económico en tanto que avance inobjetable o causa de progreso en todos los campos del orden social. En general, el pensamiento económico del siglo XVIII atacó las instituciones económicas del Antiguo Régimen, y aunque se podría decir que promovía el capitalismo naciente, Rousseau escribió antes del inicio de la Revolución Industrial. Los pensadores de la época consideraban que la servidumbre, el mayorazgo y la heredad de la tierra, la organización gremial y el proteccionismo comercial impedían la libre circulación de bienes y factores productivos y, en consecuencia, frenaban el progreso económico. En el pensamiento económico ilustrado, incluido el de 
los fisiócratas, se elogiaba la propiedad privada. No obstante, Rousseau argumentó en favor de una regresión, absolutamente imposible, al estado del "buen salvaje": en la época en que redactó sus escritos económicos aún no existía el capitalismo, aunque se opusiera al orden del Antiguo Régimen, y no se pueden utilizar para hacer proselitismo de lo que llegaría a ser el nuevo régimen, de orden capitalista.

Además, la dificultad para incluir a Rousseau en los textos de historia del pensamiento económico se agrava cuando se considera su teoría del Estado. Según los manuales universitarios, una de las consecuencias políticas de la Revolución Industrial fue el surgimiento del Estado liberal: los derechos humanos naturales se volvieron positivos y se consagraron en textos constitucionales, se desarrolló la democracia bajo el liderazgo de la burguesía y surgieron los partidos políticos modernos, etc. Como advirtió Bertrand Russell (1945), una lectura sesgada de su teoría del Estado puede utilizarse como justificación del totalitarismo, lo que es por completo incompatible con el liberalismo idílico de los antagonistas del Antiguo Régimen. En El contrato social, por ejemplo, Rousseau afirma que a partir de la vida en sociedad surge una entidad (los estudiosos señalan que se refiere al Estado) con intereses propios (la "voluntad general") que no coincide necesariamente con la "voluntad de todos" o de la "mayoría" de los miembros de la sociedad. Y esa "voluntad general”, que en su opinión es la expresión auténtica del bien común, no se puede manifestar salvo que se superen los intereses particulares, para lo que se requiere bloquear cualquier pacto entre grupos que imponga el interés de esos grupos a los demás ciudadanos. Basta dar un paso audaz y atrevido para interpretar esta idea de Rousseau como una prohibición de las asociaciones y partidos políticos.

En el pensamiento económico de Rousseau hay otro aspecto, también muy incómodo: el análisis de la desigualdad y la crítica de la propiedad privada, que es elemento central en sus escritos económicos. De hecho, uno de los principales se titula "Discurso sobre el origen de la desigualdad".

Su primera consideración sobre la propiedad privada es una negación de su legitimidad:

E1 primero a quien, después de cercar un terreno, se le ocurrió decir "Esto es mío", y halló personas bastante simples para creerle, fue el verdadero fundador de la sociedad civil. Cuántos crímenes, guerras, muertes; cuántas miserias y horrores habría ahorrado al género humano el que, arrancando las estacas o arrasando el foso, hubiese gritado a sus semejantes: “¡Guardaos de escuchar a ese impostor; estáis perdidos si olvidáis que los frutos son de todos y la tierra de nadie!" (Rousseau, 2012, 164). 
En cambio, el fundamento del pensamiento económico ilustrado es la libertad entendida como libre cambio, libre comercio de tierras y mercancías, libre contratación de trabajadores, libertad para abrir negocios. La libertad, entendida como superación de las instituciones del Antiguo Régimen, permitiría el pleno desarrollo de las potencialidades del individuo, y habría de conducir necesariamente a la prosperidad y la felicidad del género humano. Ese es el optimismo que refleja la célebre frase de Adam Smith que los manuales repiten como un mantra, glorificando la propiedad y el interés privado:

No es la benevolencia del carnicero, del cervecero o del panadero la que nos procura nuestra cena, sino el cuidado que ponen ellos en su propio beneficio. No nos dirigimos a su humanidad sino a su propio interés, y jamás les hablamos de nuestras necesidades sino de sus ventajas (Smith, 2015, 46).

Frente a los efectos benéficos que -según Smith- el interés privado tendría sobre la prosperidad pública, Rousseau ya había expuesto algunas reflexiones dignas de tenerse en cuenta:

Si se me responde que la sociedad está de tal suerte constituida que cada hombre se beneficia sirviendo a los demás, replicaré que ello sería muy aceptable si no ganase, mucho más aún, perjudicándolos. No hay ningún beneficio legítimo que no sea excedido por el que puede hacerse ilegítimamente, así como el mal ocasionado al prójimo es siempre más lucrativo que los servicios que puedan proporcionársele. No se trata pues más que de encontrar los medios de asegurar la impunidad, en persecución de lo cual, los poderosos emplean todas sus fuerzas y los débiles todas sus astucias (Rousseau, 2012, 198).

E1 análisis de la desigualdad enfría el entusiasmo liberal y pone en cuestión las promesas optimistas de la época del capitalismo naciente. Y quizá peor, la creciente desigualdad generada por el capitalismo moderno parece mostrar que eran solo otra utopía, la utopía liberal, siempre relegada al futuro, como las demás. En ese sentido, Rousseau es un pensador incómodo, una antítesis de Adam Smith: sus escritos no se limitan a constatar la decadencia del Antiguo Régimen, también advierten los males que provoca la propiedad privada, la principal institución del capitalismo naciente e incluso la institución sagrada de la futura Revolución Francesa. Para Rousseau la propiedad privada es fuente de desigualdad y de explotación, y solo es admisible, como un mal menor, en la medida en que el temor a perderla hace que los individuos cumplan las leyes. Así, en su "Discurso sobre la economía política" manifiesta:

Es sabido que el derecho de propiedad es el más sagrado de todos los derechos de los ciudadanos y, en ciertos aspectos, más importante que la propia libertad. Su respeto debe primar por encima de todo: tanto porque vela por la conservación de la vida, como por su indefensión desigual frente a las personas o su facilidad para ser violado. A fin de cuentas, la propiedad es el verdadero fundamento de la sociedad civil, garante a su vez de los compromisos con los 
ciudadanos: si los bienes no respondiesen de las personas, nada sería tan fácil como eludir los deberes y burlarse de las leyes (Rousseau, 2011, 55 y 56).

Rousseau muestra así las bases contradictorias en las que se asienta la sociedad (de su época y de la nuestra): la propiedad privada es necesaria para que los ciudadanos se obliguen a sí mismos a cumplir la ley, pero su única fuente de legitimidad es el trabajo, la cual se agota con el curso del tiempo y el aumento de la productividad:

Del cultivo de las tierras sobrevino ineluctablemente su partición; y de la propiedad, una vez conocida, se derivaron las primeras reglas de justicia, porque, para dar a cada uno lo suyo, preciso es que cada uno pueda tener algo [...] E1 trabajo es lo único que, dando derecho al cultivador sobre el producto de la tierra que ha labrado, se le da, por consecuencia, sobre el suelo, por lo menos hasta la recolección; así, de año en año, al ejercer posesión continua, se transforma fácilmente en propiedad (Rousseau, 2012, 172).

Además, antes de la interpretación optimista de Adam Smith acerca de la división del trabajo y el aumento de la productividad, Rousseau señaló que eran condiciones necesarias para la explotación y la desigualdad y, con ellas, de la miseria. Así lo expresa en su "Discurso sobre el origen de la desigualdad":

Desde el momento en que un hombre tuvo necesidad del auxilio de otro, desde que se advirtió que era útil a uno solo tener provisiones para dos, la igualdad desapareció, introdújose la propiedad, fue indispensable el trabajo y las extensas selvas se trocaron en sonrientes campiñas, que hubieron de regarse con el sudor del hombre, y en las cuales viéronse muy pronto germinar y crecer, juntamente con las semillas, la esclavitud y la miseria (Rousseau, 2012, 170).

\section{CONCLUSIONES}

Como pensador económico, Rousseau era afín a la fisiocracia y no era liberal; al menos no en el sentido smithiano del término. Su consideración en la enseñanza de la historia del pensamiento económico proporcionaría una visión más amplia e inquisitiva de la transición del Antiguo Régimen al capitalismo liberal. Pero, a diferencia de la de Smith, su obra no sirve para justificar y dar prestigio, recurriendo a parábolas ingeniosas, a una interpretación simplista de las bondades de la Revolución Industrial ni de las instituciones del nuevo modo de producción que habría de alumbrar. E1 hecho de que no sea un autor exegético es quizá la principal razón de que sea omitido en los textos de economía contemporáneos y de que se le haya negado el justo lugar que le correspondería entre los fisiócratas más eminentes. 


\section{REFERENCIAS BIBLIOGRÁFICAS}

1. Álvarez, A y J. Hurtado. "Jean-Jacques Rousseau y Karl Marx: estudio comparativo de dos críticas a la economía de mercado", Revista de Economía Institucional 10, 18, 2008, pp. 103-127.

2. Blaug, M. Teoría económica en retrospección, México DF, Fondo de Cultura Económica, 1985.

3. Boswell, J. La vida de Samuel Johnson, Madrid, Espasa, 2007.

4. Cabrales, A.; R. Nagel y J. V. Rodríguez. "It is Hobbes, not Rousseau: An experiment on voting and redistribution", Experimental Economics 15, 2012, pp. 278-308.

5. Cassirer, E. La filosofía de la Ilustración, México DF, Fondo de Cultura Económica, 1984.

6. Cervellati, M.; F. Piergiuseppe y U. Sunde. "Hobbes to Rousseau: Inequality, institutions, and development”, IZA DP n. ${ }^{\circ} 1450$, Forschungsinstitut zur Zukunft der Arbeit Institute for the Study of Labor, 2005.

7. Faiña, A.; J. López y L. Varela. "Non-taxable income and necessary consumption: The Rousseau's paradox of fiscal egalitarianism”, MPRA paper No. 32909, 2011.

8. Fridén, B. Rousseau's economic philosophy: Beyond the market of innocents, Dordrecht y Norwell, Mass., Kluwer Academic Publishers, 1998.

9. Hanley, R. P. "The political economy of freedom: Revisiting Rousseau's third discourse", University of Wisconsin Political Theory Workshop, 4 de marzo de 2011.

10. Hénaff, M. "Rousseau et l'économie politique. Système rustique et système de finances”, Etudes Françaises 25, 1989, pp. 103-128.

11. Larrère, C. "Pourquoi faudrait-il faire de Rousseau un économiste?", Cahier d'économie politique 53, 2007, pp. 115-134.

12. Markovits, F. "Rousseau et l'éthique de Clarens: une économie des relations humaines", Stanford French Review 15, 3, 1991, pp. 323-338.

13. Pignol, C. "Money, exchange and division of labour in Rousseau's economic philosophy", European Journal of History of Economic Thought 17, 2, 2010, pp. 199-228.

14. Pignol, C. "Rousseau's notion of envy: A comparison with modern economic theory", European Journal of History of Economic Thought 19, 4, 2011, pp. 529-549.

15. Rousseau, J. J. Discurso sobre la economía politica [1755], Madrid, MAIA ediciones, 2011.

16. Rousseau, J. J. El contrato social. Discurso sobre las ciencias y las artes. Discurso sobre el origen de la desigualdad [1754], México DF, Porrúa, 2012.

17. Russell, B. Historia de la filosofía [1945], Barcelona, RBA editores, 2009.

18. Schumpeter, J. A. Historia del análisis económico [1954], Barcelona, Ariel, 1982.

19. Smith, A. Investigación sobre la naturaleza y causa de la riqueza de las naciones [1776], Barcelona, Alianza Editorial, 2015.

20. Spector, C. "Rousseau et la critique de l'économie politique”, B. Bensaude y B. Bernardi, eds., Rousseau et les sciences, París, L'Harmattan, 2003, pp. 237-256.

21. Todorov, T. El espíritu de la Ilustración, Barcelona, Galaxia Gutemberg, 2008. 